Research Article

\title{
Study of prescription pattern in emergency psychiatry in a tertiary care academic hospital of a developing country: a retrospective study
}

\author{
Kamal Nath, Subrata Naskar*, Robin Victor, Kaveri Saxena
}

Department of Psychiatry, Silchar Medical College \& Hospital Silchar, India

Received: 14 December 2015 Accepted: 7 January 2016

*Correspondence to:

Dr. Subrata Naskar,

Email: nsubrata09@gmail.com

Copyright: () the author(s), publisher and licensee Medip Academy. This is an open-access article distributed under the terms of the Creative Commons Attribution Non-Commercial License, which permits unrestricted non-commercial use, distribution, and reproduction in any medium, provided the original work is properly cited.

\begin{abstract}
Background: Prescription pattern study of psychotropic drugs gives a picture of drug preference and rationality of drug use by psychiatrists of a region. The aim of the study was to explore the prescription pattern of psychotropic drugs in emergency settings in a tertiary care centre in a developing country.

Methods: A total of 1153 prescriptions were analysed in the study. Data was extracted retrospectively from the psychiatry department emergency register of a tertiary care hospital, in north-eastern India for a period of one year.

Results: The most commonly used psychotropic drug in emergency setting was found to be anxiolytic and hypnotics $(60.96 \%)$ in which clonazepam (48.6\%) was commonest. Antipsychotics followed next (14.5\%), out of which $69.6 \%$ were atypical antipsychotics with olanzapine being the commonest.

Conclusions: Use of parenteral typical antipsychotic was found to be much higher, than expected. For the benefit of the mass, supply of cost effective parenteral atypical antipsychotics is the need of the hour in this part of the world.
\end{abstract}

Keywords: Prescription pattern, Antipsychotics, Antidepressants, Mood stabilizers, Anxiolytics, Sedatives, Developing country

\section{INTRODUCTION}

According to World Health Organization (WHO) drug utilization research is "the marketing, distribution, prescription and use of drugs in a society, with special emphasis on the resulting medical, social and economic consequences." Drug utilization research again maybe descriptive or analytical type. The analytical type of study is concerned with linking the "data on drug utilization to figures on morbidity, outcome of treatment and quality of care with the ultimate goal of assessing whether drug therapy is rational or not"1 As the stigma associated with mental illness is gradually lifting with researchers correlating the aetiology of the mental illnesses with various biological agents and molecules, the importance of psychotropic drugs has come to light. In the past few decades there has been a revolution in psychopharmacology with new molecules and fixed dose combinations coming now and then, claiming their pharmacological superiority. So, now psychiatrists are facing an array of psychotropic drug inventory to choose from. This has led to a variation of prescription pattern for specific illnesses, which sometimes goes off-track than the accepted guidelines along with the concern of delayed side effects and polypharmacy. Here comes the role of prescription pattern monitoring studies (PPMS), which acts as a "tool for assessing the prescribing, dispensing and distribution of medicines."2 Numerous such studies on psychotropic medications had been conducted all over the world for this purpose, some noteworthy researches are done by Chee et $\mathrm{al}^{3}$ including 40 major psychiatric institutions and hospitals in Asia, Uchida et $\mathrm{al}^{4}$ involving different countries in East Asia, Lantz et $\mathrm{al}^{5}$ in Bronx, NY, USA.

As the awareness about the true nature of psychiatric illnesses are becoming gradually clear to the society mainly through social media and awareness camps conducted, India is gradually coming out from under the shroud of stigma that she had for psychiatry and showing interest in popularizing the discipline. Common people are showing accelerated interest with the hope of cure. Almost all psychotropic drugs are currently available in the market which are available in any other developed country. Some noticeable PPMS had been done in the past, like research done by Grover et al $2012^{6}$ in north India, Ramadas et al $2010^{7}$ in Trissur, India, Rode et al $2014^{8}$ in Bhopal, India, Ghosh et al $2013^{9}$ in Burdwan, 
India and Paul et al $2014^{10}$ in Assam, India. However, apart from a very few number of large scale studies that have been conducted for prescription pattern monitoring in India, most are small scale studies with limited study subjects. In this retrospective PPMS conducted in north eastern India, we have collected and analysed data for a period of 1 year. The approach of this study is a bit different from all other similar studies conducted, as here; we looked for the prescribing pattern of psychotropic drugs for the patients who are in need of emergency psychiatric attention only. In the emergency department, most of the patients are coming with a short history of sudden onset abnormal behaviour which is mostly undiagnosed earlier or with a history of diagnosed mental illness with sudden deterioration, associated with history of irregular treatment and comorbid physical illness. Therefore, psychiatrists, at times of emergency face a much more complicated group of patients and have to choose the psychiatric medications in most cases where the clinical pictures is not clear enough. A psychiatrist while choosing a psychotropic medication in such a case has to keep in mind the mode of action of the medication, possibility of mistaken diagnosis, risk of undiagnosed organic disorders and therefore unpredictable drug response, so on and so forth. Therefore, the study of prescription pattern in emergency psychiatry is definitely an important and interesting area to explore. With this aim, this particular study was undertaken as no such similar studies had been conducted so far in this part of the country.

Therefore, the aim is to study the prescription pattern of psychotropic drugs used in emergency cases in a tertiary care hospital.

\section{METHODS}

The study was conducted in the Department of psychiatry of Silchar Medical College \& Hospital which is a tertiary care centre and teaching hospital servicing the population of major part of lower Assam, mainly the districts of Cachar, Hailakandi and Karimganj along with the neighbouring states of Tripura, Meghalaya, Manipur and Mizoram. Assam is a state of India, situated in the north eastern part of the country south of eastern Himalayas. The hospital is an accredited post-graduate training centre for different medical disciplines. The department of psychiatry was first started in the year 1975 and postgraduate teaching was permitted in the year 2001. The hospital provides a 24 hours walk-in emergency service including out-of-hours psychiatry consultations.

When a patient approaches for emergency attention, he/she is first attended by a postgraduate resident along with an emergency medical officer in the general emergency department and provided the basic consultation and treatment required. If the attending doctor finds it necessary he refers the patient to various speciality departments according to the need for opinion, further evaluation or treatment. Thus, when a patient reaches psychiatry department, he/she is attended by a postgraduate psychiatry resident and resident physician of psychiatry who does an initial workup, forms a provisional diagnosis, treats the patient accordingly and maintains a record in the departmental emergency register.

The emergency register contains data which includes, patients hospital number, basic sociodemographic information, date and time of emergency visit, patients complaint, reason of referral, department from which patient is referred, provisional diagnosis of the patient, medication prescribed and if required, department to which patient is referred to.

This study is a retrospective analytical study which was conducted after obtaining hospital ethics committee approval. Data was extracted from the Psychiatry department emergency register for a period of one year starting from $1^{\text {st }}$ November 2014 to $31^{\text {st }}$ October 2015. The entries which were not properly filled were excluded. A total of 1153 entries were found to be complete and were included in the study.

The data was then tabulated in Microsoft Excel spread sheet under appropriate columns. The various parameters that were evaluated were:

- Average number of drugs per prescription.

- Route of drug administration prescribed.

- Percentages of psychotropic drugs with fixed dose combination prescribed.

- Percentages of drugs from the essential drug list of WHO and National list of essential medicines of India (NLEMI), prescribed.

- Types of psychotropic medication prescribed and their distribution.

Pivot charts were created in Microsoft Excel and the data was grouped accordingly. The drugs prescribed were grouped appropriately into 7 groups, the first 6 are psychotropics namely anxiolytic \& hypnotics, antipsychotics, antidepressants, mood stabilizers, antiepileptics and anticholinergics, whereas the last group is called 'others' which contains all others drugs prescribed. SPSS version 22 was used to evaluate basic descriptive statistics.

\section{RESULTS}

\section{Demographic characteristics of the study participants}

Of the total 1153 entries evaluated, it was found that 602 $(52.21 \%)$ were females and $551(47.79 \%)$ were males. The mean age of the subjects was found to be $30.88 \pm 13.38$ years and most of the subjects were from the age group of 21-30 years (34.61\%). Subjects were almost equally distributed among the Hindus (53.6\%) and Muslims (45.01\%) with slight Hindu predominance and mostly from rural population $(61.75 \%)$. Details of demographic data are tabulated in Table 1 and Figure 1. 
Evaluation of WHO recommended prescribing indicators $^{l}$

Total number of drugs prescribed in 1153 prescriptions was 1497 of which 1309 drugs were psychotropic (87.44\% of total drugs). Average number of drugs per encounter is 1.29 and average number of psychotropic drugs per encounter is 1.13 . Of the total number of drugs, oral preparation was prescribed in $89.04 \%(n=1333)$ and injectable in $10.95 \% \quad(n=164)$ cases. Fixed dose combination was prescribed in $3.82 \%$ encounters. The most popular being the combination of selective serotonin reuptake inhibitor (escitalopram 10mg) and benzodiazepine (clonazepam $0.5 \mathrm{mg}$ ) (93.18\%). Utilization of drug from the WHO's $19^{\text {th }}$ essential drug list11 was $31.39 \%$ and from the NLEMI list ${ }^{12}$ is $46.55 \%$.

The total number of drugs per prescription varied from one to a maximum of three. Monotherapy was prescribed in 438 subjects (37.9\%). Polypharmacy with 2 drugs was practised in 585 cases $(50.7 \%)$ and 147 subjects $(12.7 \%)$ received a prescription of three drugs.

The data is illustrated in Table $2 \&$ Figure 2.

Distribution of the psychotropic drugs according to types

The distribution of the various psychotropic drugs prescribed are grouped according to their pharmacological actions and shown in Table $3 \&$ Figure
3 and their distribution is shown in Table 4A-4D and Figure 4. Among the total number of drugs prescribed (n =1497), 1309 drugs were psychotropics and 188 drugs belonged to the non-psychotropic category. The most commonly prescribed category of psychotropic was found to be anxiolytic and hypnotics $(60.96 \%)$. In this group the most commonly prescribed drug was 1,4benzodiazepines like clonazepam $(48.6 \%)$, followed by lorazepam (34.8\%). Antipsychotics were the next most common category of drug (14.5\%). $69.6 \%$ of all the antipsychotics prescribed were atypical antipsychotics, among which, serotonin dopamine antagonist were preferred, and olanzapine $(75.1 \%)$ was prescribed the most. Among typical antipsychotics, haloperidol was preferred over others $(98.2 \%)$. When analysing the data on antidepressant group we found, that the most prescribed antidepressants were selective serotonin reuptake inhibitors $(74.6 \%)$, among whom escitalopram $(74.1 \%)$ was preferred over others. Among the mood stabilizers used, sodium valproate $(50.9 \%)$ and divalproex sodium (48.1\%) were prescribed in almost equal proportion, whereas among the antiepileptic group sodium valproate was preferred over all others $(56.2 \%)$. Trihexyphenidyl hydrochloride was the only centrally acting anticholinergic drug used in prescriptions. The other group contains drugs like antipyretics, antimigraine like flunarizine, hepatoprotectives, NMDA antagonists, NSAIDS, opioid agonists, nootropics, proton pump inhibitors, vitamins or iron supplements and comprised of $12.55 \%$ of the total drugs prescribed.

Table 1: Demographic data of the total number of subjects.

\begin{tabular}{|lllllll|}
\hline & Female & $\%$ & Male & $\%$ & Total patients & $\%$ \\
\hline Total & 602 & $100.00 \%$ & 551 & $100.00 \%$ & 1153 & $100.00 \%$ \\
\hline Age & & & & & & \\
\hline $1-10$ & 3 & $0.50 \%$ & 3 & $0.54 \%$ & 6 & $0.52 \%$ \\
\hline $11-20$ & 189 & $31.40 \%$ & 87 & $15.79 \%$ & 276 & $23.94 \%$ \\
\hline $21-30$ & 203 & $33.72 \%$ & 196 & $35.57 \%$ & 399 & $34.61 \%$ \\
\hline $31-40$ & 108 & $17.94 \%$ & 119 & $21.60 \%$ & 227 & $19.69 \%$ \\
\hline $41-50$ & 63 & $10.47 \%$ & 86 & $15.61 \%$ & 149 & $12.92 \%$ \\
\hline $51-60$ & 25 & $4.15 \%$ & 36 & $6.53 \%$ & 61 & $5.29 \%$ \\
\hline $61-70$ & 9 & $1.50 \%$ & 17 & $3.09 \%$ & 26 & $2.25 \%$ \\
\hline $71-80$ & 2 & $0.33 \%$ & 7 & $1.27 \%$ & 9 & $0.78 \%$ \\
\hline Religion & & & & & & \\
\hline Christian & 0 & $0.00 \%$ & 2 & $0.36 \%$ & 2 & $53.17 \%$ \\
\hline Hindu & 300 & $49.83 \%$ & 318 & $57.71 \%$ & 618 & $45.01 \%$ \\
\hline Muslim & 297 & $49.34 \%$ & 222 & $40.29 \%$ & 519 & $1.21 \%$ \\
\hline Others & 5 & $0.83 \%$ & 9 & $1.63 \%$ & 14 & $61.75 \%$ \\
\hline Domicile & & & & & & $38.25 \%$ \\
\hline Rural & 357 & $59.30 \%$ & 355 & $64.43 \%$ & 712 & 441 \\
\hline Urban & 245 & $40.70 \%$ & 196 & $35.57 \%$ & & \\
\hline
\end{tabular}


Table 2: Distribution of data on who recommended prescribing indicators.

Prescribing indicators

Type of treatment

$\begin{array}{ll}\text { Drug therapy } & 912(79 \%)\end{array}$

Psychotherapy alone $241(21 \%)$

Fixed dose combination

Used $44(3.816 \%)$

Not used $1109(96.18 \%)$

Mode of drug administration

Oral preparation $1333(89.04 \%)$

Intravenous $164(10.95 \%)$

Number of drugs per prescription

One

$438(37.9 \%)$

Two

$585(50.7 \%)$

Three $147(112.7 \%)$

Table 3: Distribution of the various psychotropic drugs prescribed are grouped according to their pharmacological actions.

\begin{tabular}{|llll|}
\hline Drugs & $\mathbf{N}$ & \% of total drugs & \% of total psychotropics \\
\hline Antidepressant & 150 & 10.02 & 11.45 \\
\hline Antiepileptic & 16 & 1.06 & 1.2 \\
\hline Antipsychotic & 191 & 12.75 & 14.5 \\
\hline Anxiolytic \& hypnotic & 798 & 53.3 & 60.96 \\
\hline Mood stabilizer & 106 & 7.08 & 8.09 \\
\hline Anticholinergic & 48 & 3.20 & 3.66 \\
\hline Others & 188 & 12.55 & \\
\hline Grand total & 1497 & 100 & \\
\hline
\end{tabular}

Table 4A: Distribution of prescribed anxiolytics \& hypnotics.

\begin{tabular}{|c|c|c|c|}
\hline \multicolumn{4}{|c|}{ Anxiolytics \& hypnotics } \\
\hline \multirow{7}{*}{ Benzodiazepines } & \multirow{6}{*}{ 1,4 benzodiazepines } & Clonazepam & 388 \\
\hline & & Lorazepam & 278 \\
\hline & & Chlordiazepoxide & 16 \\
\hline & & Diazepam & 3 \\
\hline & & Oxazepam & 1 \\
\hline & & Etizolam & 1 \\
\hline & 1, 5 benzodiazepines & Clobazam & 97 \\
\hline Non-benzodiazepines & Zolpidem & & 14 \\
\hline
\end{tabular}

Table 4B: Distribution of prescribed antipsychotics.

\section{Antipsychotics}

\begin{tabular}{|llll|}
\hline \multirow{2}{*}{ Typical } & & Haloperidol & 57 \\
\cline { 3 - 3 } & & Chlorpromazine & 1 \\
\hline \multirow{3}{*}{ Atypical } & $\begin{array}{l}\text { Serotonin dopamine } \\
\text { antagonist }\end{array}$ & Olanzapine & 100 \\
\cline { 2 - 3 } & \begin{tabular}{l} 
Risperidone \\
\cline { 2 - 3 }
\end{tabular} & Quetiapine & 18 \\
\cline { 2 - 4 } & $\begin{array}{l}\text { Dopamine partial } \\
\text { agonist }\end{array}$ & Aripiprazole & 2 \\
\hline
\end{tabular}


Table 4C: Distribution of prescribed antidepressants.

\begin{tabular}{|llc|}
\hline \multirow{3}{*}{ SSRI } & \multicolumn{2}{c|}{ Antidepressants } \\
& Escitalopram & 83 \\
\cline { 2 - 3 } & Paroxetine & 15 \\
\cline { 2 - 3 } & Sertraline & 14 \\
\hline \multirow{2}{*}{ CA } & Amitriptyline & 30 \\
\cline { 2 - 3 } & Imipramine & 4 \\
\hline SNRI & Desvenlafaxine & 3 \\
\hline NASA & Mirtazapine & 1 \\
\hline
\end{tabular}

Table 4D: Distribution of prescribed antiepileptic, mood stabilizers, anticholinergic \& other medications.

\begin{tabular}{|c|c|c|}
\hline \multicolumn{3}{|c|}{$\begin{array}{l}\text { Antiepileptic, mood stabilizers, anticholinergic \& } \\
\text { other medications }\end{array}$} \\
\hline \multirow{4}{*}{ Antiepileptic } & Eslicarbazepine & 2 \\
\hline & Gabapentin & 4 \\
\hline & Phenytoin & 1 \\
\hline & Sodium valproate & 9 \\
\hline \multirow{3}{*}{$\begin{array}{l}\text { Mood } \\
\text { stabilizer }\end{array}$} & Carbamazepine & 1 \\
\hline & Divalproex & 51 \\
\hline & Sodium valproate & 54 \\
\hline $\begin{array}{l}\text { Anti- } \\
\text { cholinergic }\end{array}$ & $\begin{array}{l}\text { Trihexyphenidyl } \\
\text { hydrochloride }\end{array}$ & 48 \\
\hline Others & $\begin{array}{l}\text { Antipyretic, calcium } \\
\text { channel blocker, } \\
\text { hepatoprotective, } \\
\text { NMDA antagonist, } \\
\text { NSAIDs, opioid } \\
\text { agonist, nootropic, PPI, } \\
\text { vitamin, iron } \\
\text { supplement }\end{array}$ & 188 \\
\hline $\begin{array}{l}\text { NMDA - N-1 } \\
\text { NSAIDS }-\mathrm{n}\end{array}$ & roidal anti-inflammatory & Imp inhibi \\
\hline
\end{tabular}

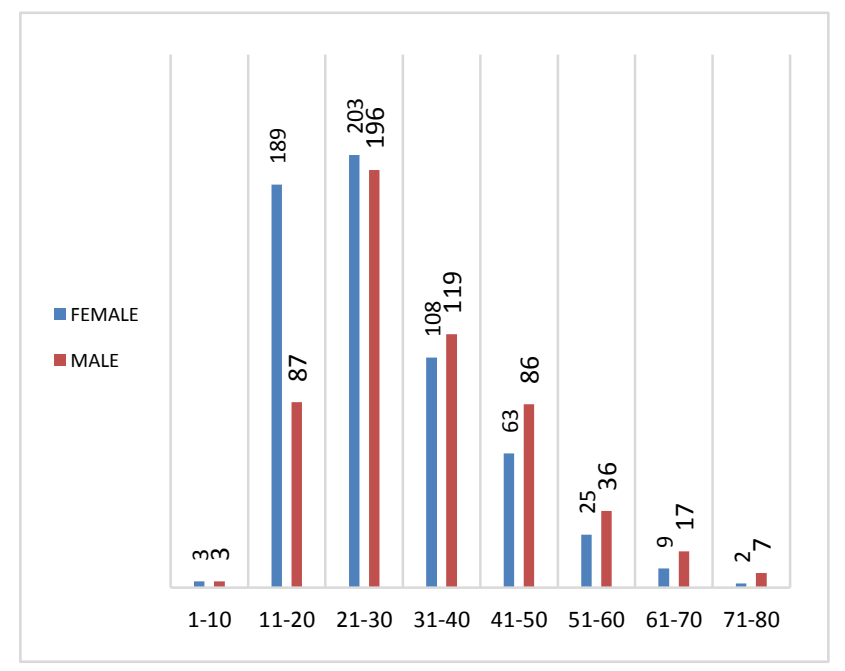

Figure 1: Distribution of study subjects according to age and gender.
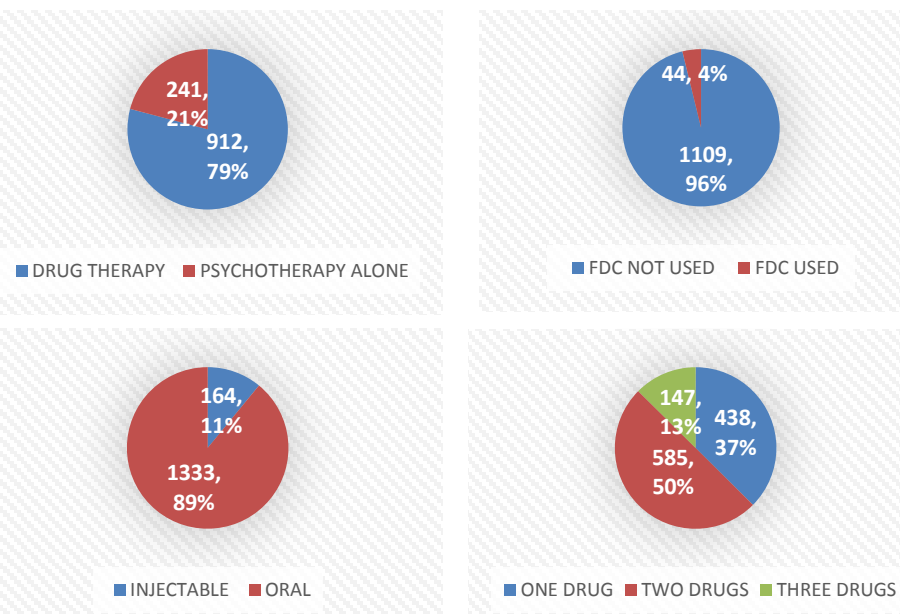

Figure 2: Pie diagrams showing distribution of data on world health organization recommended prescribing indicators.

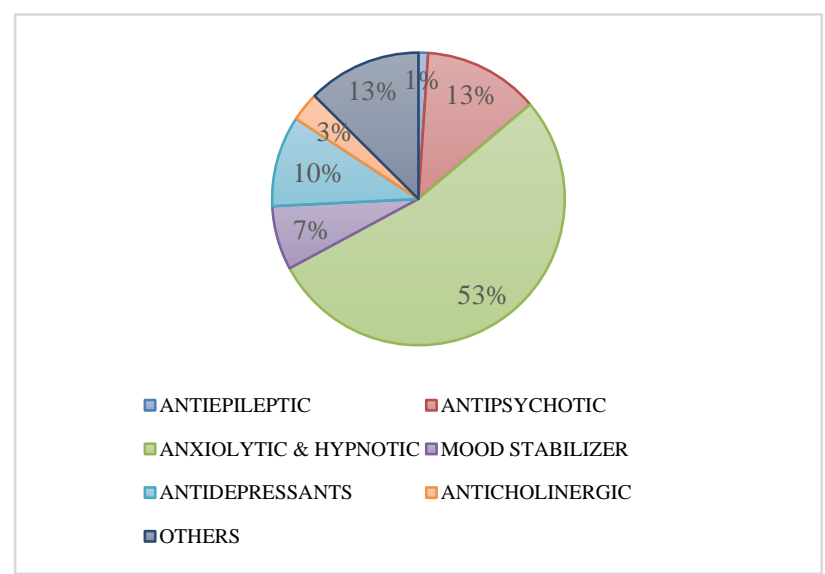

Figure 3: Distribution of the various psychotropic drugs prescribed grouped according to their pharmacological actions.

\section{DISCUSSION}

\section{Sociodemographic characteristics}

We found maximum patients attending the emergency in need of psychiatric consultation are in their third decade of life $(34.61 \%)$ and the mean age of the subjects was found to be $30.88 \pm 13.38$ years. Most of them are females $(52.21 \%)$, Hindu by religion $(53.6 \%)$ and from a rural background $(61.75 \%)$. Ang et $\mathrm{al}^{13}$ in their study conducted at Singapore found the mean age to be 35.5 years, with a female $(62.8 \%)$ predominance over males $(37.2 \%)$. Kelkar et $\mathrm{al}^{14}$ reported that most of the patients were below 24 years of age, almost equal number from both genders with slight male predominance (51\%). Keertish et $\mathrm{al}^{15}$, Shahid et $\mathrm{al}^{16}$ and Shakya et $\mathrm{al}^{17}$ from Nepal reported a male predominance in patients in need of emergency psychiatry consultation over females. 

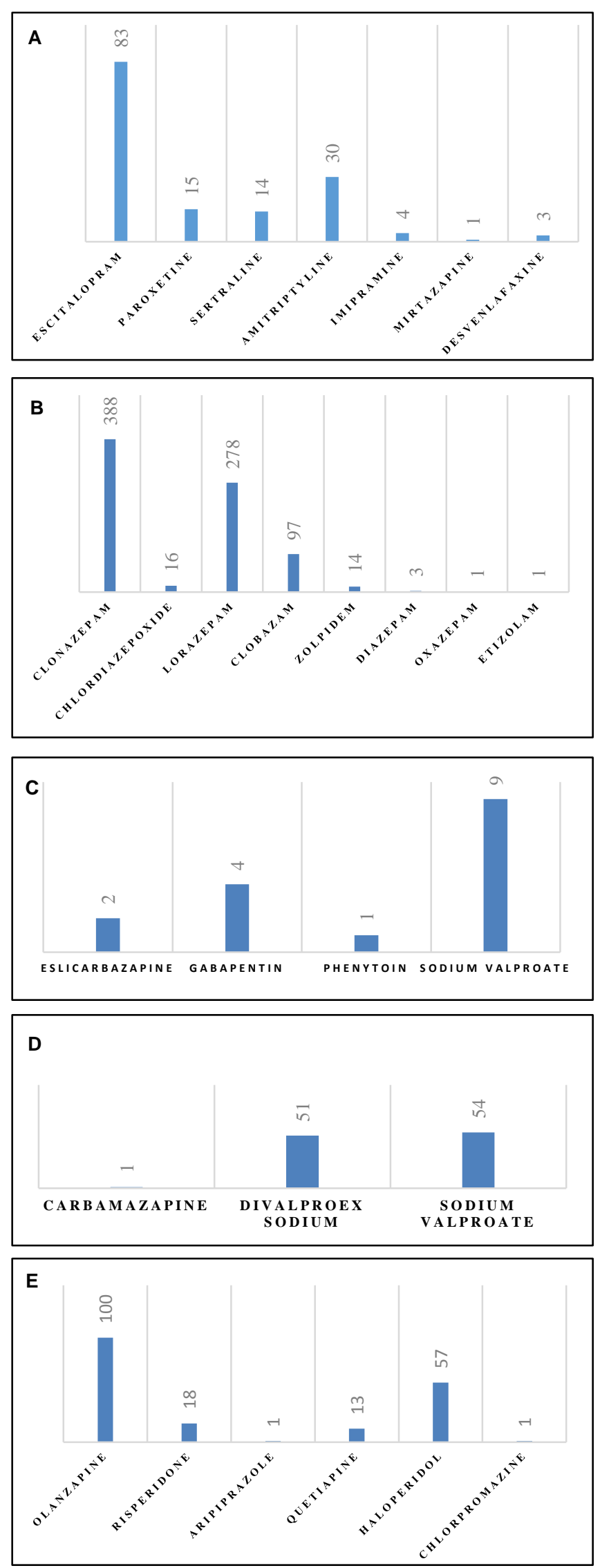

Figure 4: Distribution of psychotropic drugs prescribed according to types. (A): Antidepressants; (B): Anxiolytics \& hypnotics; (C): Antiepileptics; (D): Mood stabilizers; (E): Antipsychotics.
Prescription pattern analysis as per the WHO/INRUD drug use indicators

International Network for Rational Use of Drugs (INRUD) and the World Health Organization (WHO) recommended the use of certain indicators to evaluate the rational use of drugs. Those are "Average number of drugs per encounter, percentage of drugs prescribed by generic name, percentage of encounters with an antibiotic prescribed, percentage of encounters with an injection prescribed, percentage of drugs prescribed from essential medicines list or formulary". ${ }^{\circ}$

\section{Average number of drug used per prescription}

In this study, we found that the average number of drugs prescribed per prescription is 1.29 . This finding is comparable to numerous other studies like Ghosh et al, ${ }^{9}$ who in their study conducted at a tertiary care centre in Burdwan, India found the average number of drugs per prescription to be 1.07. Similar other studies however, have reported slightly higher values. Studies conducted by Paul et $\mathrm{al}^{10}$ in Assam, India, Thakkar et $\mathrm{al}^{18}$ in Mumbai, India and Rode et $\mathrm{al}^{8}$ in Bhopal, India on prescription pattern of psychotropic drugs found the average number of drugs per prescription as 2.20, $2.01 \pm 1.03$ and $2.1 \pm 0.8$ respectively.

\section{Mode of administration}

We have found that oral preparation of drug is preferred over injectable preparation even in case of psychiatric emergencies. Injectable drugs are used in only $10.95 \%$ of cases. Similar practice was observed in study by Sharma et al19 in Delhi, India where in 16\% cases injectable drugs were used. However, our finding is much higher than reports of other similar studies, like Rode et $\mathrm{al}^{8}$ reported that in only $3.3 \%$ cases injectable drugs were used. Ghosh et $\mathrm{al}^{9}$ reported that on an average $4.59 \%$ of the drugs prescribed were injectable, whereas, Paul et $\mathrm{al}^{10}$ reported that only in $5.01 \%$ of their prescriptions had injectable drugs. Drugs that were used mainly in injectable forms were haloperidol, lorazepam and thiamine preparation. No long acting injectable drug was prescribed in any emergency situation.

\section{Use of fixed dose combination}

The study revealed that fixed dose combination was used in only $3.82 \%$ of subjects. In $93.18 \%$ cases the combination used was tab escitalopram $10 \mathrm{mg}$ with tab clonazepam $0.5 \mathrm{mg}$ (a combination of selective serotonin reuptake inhibitors and benzodiazepine) followed by tab diazepam $2 \mathrm{mg}$ with imipramine $25 \mathrm{mg}$ (benzodiazepine with tricyclic antidepressant). This figure and combination is much less than any other similar studies. Rode et $\mathrm{al}^{8}$ and Thakkar et $\mathrm{al}^{18}$ reported that $20.58 \%$ and $22.5 \%$ of prescriptions contained fixed dose combination, and the most popular was a combination of trifluoperazine (typical anti-psychotic) plus trihexyphenidyl hydrochloride (central anticholinergic). 
As the use of atypical antipsychotics is increasing, the traditional use of typical antipsychotics and anticholinergic combination are becoming rare now days. Our study reflects this particular trend also.

\section{Use of drug from essential drug list (WHO \& Indian)}

We found that utilization of drug from the WHO's $19^{\text {th }}$ essential drug list $^{11}$ was $31.39 \%$ and from the NLEMI list $^{12}$ is $46.55 \%$. The essential drug list was created to promote rational use of medication to ensure cost, safety and efficacy. This finding is at par with similar other studies. $^{8}$ It shows that a good and healthy prescription pattern is followed in this particular institute.

\section{Monotherapy vs polytherapy}

Maximum number of drugs prescribed in a single prescription was three. Monotherapy was practised in a significant $37.9 \%$ subjects. Two and three drugs per prescription were found in $50.7 \%$ and $12.7 \%$ of cases respectively. Psychiatric polypharmacy is "the use of two or more psychiatric medications in the same patient or using two or more medications (of the same chemical class or same pharmacologic actions) to treat the same condition". ${ }^{20}$ This result is at par with findings by Sarkar et $\mathrm{al}^{21}$ and Paul et $\mathrm{al}^{10}$ who reported that polypharmacy was practised in $76.6 \%$ and $46.63 \%$ encounters.

\section{Observed drug use pattern}

In this study, we observed that among the psychotropic drugs, anxiolytic and hypnotics $(60.96 \%)$ were the most commonly used drugs in all the prescriptions followed by antipsychotics (14.5\%) and antidepressants (11.45\%). $8.09 \%$ of the drugs were mood stabilizers, whereas only $3.66 \%$ of the total drugs were centrally acting anticholinergics.

International studies like one conducted by Ernst et $\mathrm{al}^{22}$ at Massachusetts General Hospital, Boston, USA in 2006 reported that in emergency management of psychiatry cases, "prescriptions most often included antidepressants (64\%), benzodiazepines (25\%), nonbenzodiazepine sedatives $(20 \%)$, anti-psychotics $(18 \%)$, and mood stabilizers $(10 \%)$ ".

We found very minimal Indian research data on prescription pattern of drugs in psychiatry emergency as most of the Indian studies like this, gave a general data of psychiatry prescription pattern which included the inpatient, outpatient and emergency. Rode et al's ${ }^{8}$ study showed $30.04 \%$ of all psychotropics prescribed were anxiolytics which was followed by antidepressants $(25.46 \%)$. Antipsychotic use was found in $25.36 \%$ of the total drug prescribed. Paul et $\mathrm{al}^{10}$ reported that of all psychotropics, antipsychotics were the most used one (49.67\%). Sedative hypnotics were used in $12.2 \%$ and antidepressants in only $2.17 \%$ cases. So, in our study we saw that this hospital, a tertiary care centre, followed the basic psychotropic drug prescribing pattern as reported by most of the Indian studies except few, which shows high rates of anxiolytics and hypnotics use. When compared with the international studies we found that percentage of anxiolytics and hypnotics use is almost the same except significantly higher use of antidepressants in the international studies.

Our data reflects the prescription pattern of the psychotropic drugs in emergency only. But most of the data of other studies mentioned above reflects the prescription pattern of psychotropic medications prescribed in all types of setup, including inpatient, outpatient department, as well as emergency. Probably that is why, use of anxiolytics and hypnotics are little bit higher in our studies than others, where use of antipsychotics and antidepressants are higher, as expected.

\section{Anxiolytic \& hypnotic prescribing pattern}

Among the Anxiolytic and hypnotic groups, we found a significantly higher use of benzodiazepines (98.24\%) over non-benzodiazepines $(1.75 \%)$. Zolpidem was the only non-benzodiazepine prescribed. Among the benzodiazepines, 1, 4-benzodiazepine use was predominant $(87.62 \%)$, followed by 1,5 benzodiazepines (12.3\%). Clonazepam use was highest (56.47\%), followed by lorazepam $(40.6 \%)$ in the 1,4 BNZ group and the only 1, 5 BNZ used was Clobazam. Grover et $\mathrm{al}^{23}$ in their multicentre study found that among the benzodiazepines clonazepam was most popularly used (64\%), followed by lorazepam (14.3\%). Similar findings were reported by Rode et $\mathrm{al}^{8}$, namely $51.83 \%$ for clonazepam and $32.32 \%$ for lorazepam.

\section{Antipsychotic prescribing pattern}

Among antipsychotics, the use of atypical group was significantly higher (69.63\%) than the typical group $(30.36 \%)$. Among the atypical group, serotonin dopamine antagonists $(98.49 \%)$ were used much more than the dopamine partial agonists $(1.5 \%)$. When the SDA group was analysed, we found that olanzapine was mostly the drug of choice $(76.33 \%$ among the SDAs, $52.35 \%$ of total antipsychotics), followed by risperidone (13.74\% among the SDAs, $9.4 \%$ of total antipsychotics) and quetiapine (9.9\% among the SDAs, $6.8 \%$ of total antipsychotics). DPA were used only in 2 patient, both were aripiprazole. In the typical group, haloperidol was used the most (98.27\% among typical group, $29.84 \%$ among total antipsychotics). Interestingly, clozapine was not used in a single prescription.

Rode et $\mathrm{al}^{8}$ in their study also mentioned about the preference of atypical antipsychotics (65.34\%) among psychiatrists over the typical ones $(34.66 \%)$. Ramadas et $\mathrm{al}^{7}$ in their study, conducted at Trissur, Kerala, India found similar results (atypical - 59\%). On the other hand, Ghosh et $\mathrm{al}^{24}$ reported a much higher usage of atypical antipsychotics $(87.15 \%)$. Among the atypical antipsychotics, Olanzapine was prescribed the highest 
according to Ghosh et $\mathrm{al}^{9}$ (Burdwan) (77.06\%), Paul et $\mathrm{al}^{10}(51.04 \%)$, Rode et $\mathrm{al}^{8}$ (Bhopal) $(45.13 \%)$ and Banerjee et $\mathrm{al}^{25}$ (Nepal) (34.3\%). Risperidone was found to be the next popular atypical antipsychotic as found by Thakkar et $\mathrm{al}^{18}(13 \%)$, Paul et $\mathrm{al}^{10}(17.14 \%)$, Banerjee et al $25(17.4 \%)$ and Rode et $\mathrm{al}^{8}(7.22 \%)$. Among the typical antipsychotics, similar to our study, haloperidol was prescribed more than any other drug of its group as mentioned by Ghosh et $\mathrm{al}^{9}$ (11\% of total antipsychotics), Rode et $\mathrm{al}^{8}$ (34.66\% of total antipsychotics), Thakkar et $\mathrm{al}^{18}$ (33\% of total antipsychotics).

The use of typical antipsychotics is found to be a little higher in our study than some other studies mentioned above which is most likely due to the fact that our data is regarding the prescription pattern of the emergency psychiatry services only and in that setup the primary concern many a times is to control the violent and aggressive behaviour of a psychotic patient, which requires parenteral use most of the time. Along with that, the non-availability of parenteral preparation of atypical antipsychotics in this area led to higher use of typical parenteral drugs like haloperidol.

\section{Antidepressant prescribing pattern}

The most common group prescribed among the antidepressants was selective serotonin reuptake inhibitors (SSRI) (74.66\%), followed by tricyclic antidepressants (TCA) $(22.66 \%)$. Among the SSRI group, escitalopram was the most commonly prescribed drug (74.10\% of the SSRIs, $55.33 \%$ of total antidepressants), followed by paroxetine (13.39\% of the SSRIs, $10 \%$ of total antidepressants), and sertraline (12.5\% of the SSRIs, $9.3 \%$ of total antidepressants). Among the TCAs, Amitriptyline was preferred over others $(88.23 \%$ of TCAs, $20 \%$ of total antidepressants), followed by imipramine $(11.76 \%$ of TCAs, $2.6 \%$ of total antidepressants).

According to Chee et $\mathrm{al}^{3}$ in their research on prescription pattern of antidepressants in Asia, conducted in Taiwan, SSRI were found to be preferred over other antidepressants. Similar findings were found by Uchida et al 4 who conducted a similar study across 5 countries including China, Japan, Korea, Singapore and Taiwan and found that $77 \%$ of all antidepressants used were SSRIs. Shiroma et $\mathrm{al}^{26}$ (Minnesota, USA) also gave similar conclusion. Grover et $\mathrm{al}^{27}$ found that Selective serotonin reuptake inhibitors (SSRIs) formed $71.4 \%$ of the total prescriptions.

Similar to our studies, Escitalopram was prescribed the most among the SSRIs according to Grover et al $2012^{6}$ $(34.4 \%)$ and Rode et $\mathrm{al}^{8}(39.21 \%)$. Indian Psychiatric society's study on antidepressant prescription pattern ${ }^{28}$ commented that "escitalopram is the most commonly prescribed antidepressant in India and SSRIs are the most commonly prescribed class of antidepressants". We also found that among total antidepressants prescribed, prescription of Amitriptyline and imipramine was almost similar to Rode et $\mathrm{al}^{8}(24.1 \%)$ and $(16.55 \%)$. However, Grover et al $^{6} 2012$ reported a much less use of TCAs like Amitriptyline $(3.7 \%)$ and a much higher use of other SSRI's like sertraline (20.3\%) in unipolar depressive disorder cases. Use of other group of antidepressants like SNRI, NASA is much less in our study when compared to other similar Indian studies like Grover et $\mathrm{al}^{28}$ (SNRI $11.3 \%$, NASA $-6.1 \%$ ).

\section{Mood stabilizer prescribing pattern}

Sodium valproate $(50.94 \%$ of total mood stabilizers) and divalproex sodium (48.11\%) were almost equally preferred among the various mood stabilizers used. Grover et $\mathrm{al}^{6}$ reported that among mood stabilizers valproate was preferred over others. In contrast to this Rode et $\mathrm{al}^{8}$ however, found that carbamazepine $(49.4 \%)$ was the preferred mood stabilizer over valproate (40.96\%). Interestingly, lithium was not used in a single prescription in our study, whereas other studies mentioned about its use. This may be due to the fact that we evaluated the emergency prescription pattern only in contrast to other studies where they included patients from outpatient, inpatient as well as emergency department. Lithium is a drug with narrow therapeutic index and needs to be started cautiously after proper hepatic and renal function evaluation. That is probably the fact why, psychiatrists in this tertiary care centre, preferred not to use lithium over other mood stabilizers in cases of emergency.

\section{Anticholinergics prescribing pattern}

Trihexyphenidyl hydrochloride (THP-HCL) was the only centrally acting anticholinergic used $(3.66 \%$ of total drugs prescribed). Rode et $\mathrm{al}^{8}$ and Ghosh et $\mathrm{al}^{9}$ also reported about the predominant use of this drug among this group. However, trihexyphenidyl hydrochloride was used much less than what is reported by other studies. Rode et $\mathrm{al}^{8} \&$ Ramadas et $\mathrm{al}^{7}$ reported $9.79 \%$ \& $17 \%$ of patients received THP-HCL respectively.

\section{Antiepileptic prescribing pattern}

Among the drugs which were exclusively used as antiepileptic in cases of epilepsy, sodium valproate $(56.25 \%)$ was the majority, followed by gabapentin $(25 \%)$. It is to be noted that the status epilepticus cases in this tertiary care centre are managed by the department of medicine and not by the psychiatry department.

\section{Others}

Other associated non-psychotropic medications that were included in the prescriptions comprised of $12.55 \%$ of the total drugs prescribed. In this group, vitamins including thiamine were prescribed the most $(51.06 \%)$, followed by hepatoprotective agents like ursodeoxycholic acid $(19.14 \%)$. 


\section{CONCLUSION}

This study was a novel attempt to see the pattern of emergency psychiatry service utilizations in a tertiary care centre in the north eastern part of India. The mean age of the total sample was $30.88 \pm 13.38$ years. We did not find any specific pattern or association of the sociodemographic variables of the study subjects with the patients attending emergency department for emergency psychiatric care. However, on evaluating the prescription pattern, we found that the average number of drugs prescribed per prescription was 1.29 , most of the drugs were administered orally even in emergency situations $(89 \%)$, the use of FDC was very less $(3.816 \%)$ and most of the prescriptions contained two $(50 \%)$ or more $(13 \%)$ number of drugs. All these findings are consistent with all major national and international studies available with minor differences in some points. Usage of drugs from the WHO's 19th essential drug list ${ }^{11}$ was $31.39 \%$ and from the NLEMI $\operatorname{list}^{12}$ is $46.55 \%$ which indicates a rational approach for management of psychiatric patients even in emergency conditions.

We found that anxiolytics and hypnotics were used most commonly among all groups of drugs $(53.3 \%)$, which will obviously be high for management of acutely emotionally distressed persons visiting emergency. We found a much lesser use of non-benzodiazepine group of drugs; this is probably due to two factors. Firstly, because of higher cost and secondly, because, they are not available in parenteral form and not freely available all throughout the year. The use of antipsychotics (12.75\%) and antidepressants (10.02\%) was almost equal followed by use of mood stabilizers (7.08\%). Antiepileptic use as such was very low $(1.06 \%)$, as the emergency cases with seizure disorder including status epilepticus were managed by department of medicine. Apart from these, many other drugs which are used at times in emergency management constituted about $(12.55 \%)$ of the total drugs prescribed.

Our study has shown some significant differences in pattern of psychotropic drug use in this part of the world. More such studies are required to be conducted in this region, which evaluates the adverse effects associated with the use of psychotropic agents in emergency, which may help to choose the better psychotropic agent with low side effect profile in such setup. The point that we want to highlight at the end of the study is that, the availability of a parenteral preparation of atypical antipsychotics will go a long way in restricting the use of typical antipsychotics particularly haloperidol, thereby avoiding many undesired side effects. The time period, in which the study was conducted, north eastern India faced a massive crisis of supply of atypical parenteral antipsychotics, resulting in frequent use of typical antipsychotics like haloperidol. Supply of cost effective, parenteral atypical antipsychotics is the need of the hour for appropriate management of the masses.
Funding: No funding sources

Conflict of interest: None declared

Ethical approval: The study was approved by the Institutional Ethics Committee

\section{REFERENCES}

1. World Health Organization. Introduction to drug utilization research introduction to drug utilization research, 2003.

2. Jain S, Upadhyaya P, Goyal J, Kumar A, Jain P, Seth V, et al. A systematic review of prescription pattern monitoring studies and their effectiveness in promoting rational use of medicines. Perspect Clin Res. 2015;6(2):86-90.

3. Chee KY, Tripathi A, Avasthi A, Chong MY, Sim $\mathrm{K}$, Yang SY, et al. International study on antidepressant prescription pattern at 40 major psychiatric institutions and hospitals in Asia: A 10year comparison study. Asia Pac Psychiatry. 2015;7(4):366-74.

4. Uchida N, Chong MY, Tan CH, Nagai H, Tanaka M, Lee MS, et al. International study on antidepressant prescription pattern at 20 teaching hospitals and major psychiatric institutions in East Asia: Analysis of 1898 cases from China, Japan, Korea, Singapore and Taiwan. Psychiatry Clin Neurosci. 2007;61(5):522-8.

5. Lantz MS, Louis A, Lowenstein G, Kennedy GJ. A longitudinal study of psychotropic prescriptions in a teaching nursing home. Am J Psychiatry. 1990;147(12):1637-9.

6. Grover S, Kumar V, Avasthi A, Kulhara P. An audit of first prescription of new patients attending a psychiatry walk-in-clinic in north India. Indian $\mathbf{J}$ Pharmacol. 2012;44(3):319-25.

7. Ramadas S, Kuttichira P, Sumesh TP, Ummer SA. A study of an antipsychotic prescription pattern of patients with schizophrenia in a developing country. Indian J Psychol Med. 2010;32(1):13-6.

8. Rode S, Ajagallay R, Salankar H, Sinha U. A study on drug prescribing pattern in psychiatry out-patient department from a tertiary care teaching hospital. Int J Basic Clin Pharmacol. 2014;3(3):517.

9. Ghosh S, Bhattacharyya S, Dalai CK. Antipsychotic prescribing pattern in a tertiary care hospital of eastern india. J Drug Deliv Ther. 2013;3(4):38-42.

10. Paul PK, Konwar M, Das S. To study the prescribing pattern of antipsychotic drugs in a tertiary care hospital of assam. Int J Pharm Pharm Sci. 2014;6(4):4-6.

11. WHO. WHO Model Lists of Essential Medicines. http://www.who.int/medicines/publications/essential medicines/en/. Accessed November 11, 2015.

12. Gitanjali B, Manikandan S. National list of essential medicines of India: The way forward. J Postgrad Med. 2012;58(1):68. doi:10.4103/0022-3859.93258.

13. Ang AW, Ko SM, Kua EH. Psychiatric referrals from an accident and emergency department in Singapore. J Accid Emerg Med. 1995;12(2):119-22. 
14. Kelkar DK, Chaturvedi SK, Malhotra S. A study of emergency psychiatric referrals in a teaching general hospital. Indian J Psychiatry. 1982;24(4):366-9.

15. Keertish N, Sathyanarayana MT, Kumar BGH, Singh N, Udagave K. Pattern of psychiatric referrals in a tertiary care teaching hospital in southern India. J Clin Diagn Res. 2013;7(8):1689-91.

16. Shahid M, Khan MZ, Ejaz K, Nakeer R, Iftikhar S. Profile of psychiatric patients presenting to a tertiary care emergency department of Karachi. J Coll Physicians Surg Pak. 2015;25(5):386-8.

17. Shakya DR, Shyangwa PM, Shakya R. Psychiatric emergencies in a tertiary care hospital. JNMA J Nepal Med Assoc. 2008;47(169):28-33.

18. Thakkar KB, Jain MM, Billa G, Joshi A, Khobragade AA. A drug utilization study of psychotropic drugs prescribed in the psychiatry outpatient department of a tertiary care hospital. J Clin Diagn Res. 2013;7(12):2759-64.

19. Sharma S, Chadda R, Rishi R, Gulati RK, Bapna J. Prescribing pattern and indicators for performance in a psychiatric practice. Int $\mathbf{J}$ Psychiatry Clin Pract. 2003;7(4):231-8.

20. Wheeler Vega JA, Mortimer AM, Tyson PJ. Conventional antipsychotic prescription in unipolar depression, I: an audit and recommendations for practice. J Clin Psychiatry. 2003;64(5):568-74.

21. Sarkar P, Chakraborty K, Misra A, Shukla R, Swain SP. Pattern of psychotropic prescription in a tertiary care center: a critical analysis. Indian J Pharmacol. 2013;45(3):270-3.

22. Ernst CL, Bird SA, Goldberg JF, Ghaemi SN. The prescription of psychotropic medications for patients discharged from a psychiatric emergency service. J Clin Psychiatry. 2006;67(5):720-6.

23. Grover S, Avasthi A, Sinha V, Lakdawala B, Bathla M, Sethi S, et al. Indian psychiatric society multicentric study: prescription patterns of psychotropics in India. Indian $J$ Psych. 2014;56(3):253-64.

24. Folstein M, Folstein S, McHugh R. Mini-Mental State Examination (MMSE : A practical method for grading the cognative state of patients for the clinicians. J Psychiatr Res. 1975;12:189-98.

25. Banerjee I, Roy B, Sathian B, Banerjee I, Chakraborty PK, Saha A. Socio demographic profile and utilization pattern of antipsychotic drugs among schizophrenic inpatients: a cross sectional study from western region of Nepal. BMC Psychiatry. 2013;13:96.

26. Shiroma PR, Geda YE, Mohan A, Richardson J. Antidepressant prescription pattern in a hospice program. Am J Hosp Palliat Care. 2011;28(3):193-7.

27. Grover S, Avasthi A. Anti-psychotic prescription pattern: A preliminary survey of Psychiatrists in India. Indian J Psych. 2010;52(3):257-9.

28. Grover S, Avasth A, Kalita K, Dalal PK, Rao GP, Chadda RK, et al. IPS multicentric study: Antidepressant prescription patterns. Indian J Psych. 2013;55(1):41-5.

Cite this article as: Nath K, Naskar S, Victor R, Saxena K. Study of prescription pattern in emergency psychiatry in a tertiary care academic hospital of a developing country: a retrospective study. Int J Basic Clin Pharmacol 2016;5:45-54. 